\title{
Pacing: A concept analysis of a chronic pain intervention
}

\author{
Kathryn Jamieson-Lega MScOT, Robyn Berry MScOT, Cary A Brown PhD
}

\begin{abstract}
K Jamieson-Lega, R Berry, CA Brown. Pacing: A concept analysis of a chronic pain intervention. Pain Res Manag 2013;18(4):207-213.

BACKGROUND: The intervention of pacing is regularly recommended for chronic pain patients. However, pacing is poorly defined and appears to be interpreted in varying, potentially contradictory manners within the field of chronic pain. This conceptual lack of clarity has implications for effective service delivery and for researchers' ability to conduct rigorous study. An examination of the background literature demonstrates that while pacing is often one part of a multidisciplinary pain management program, outcome research is hindered by a lack of a clear and shared definition of this currently ill-defined construct.

OBJECTIVES: To conduct a formal concept analysis of the term 'pacing'. METHODS: A standardized concept analysis process (including literature scoping to identify all uses of the concept, analysis to determine defining attributes of the concept and identification of model, borderline and contrary cases) was used to determine what the concept of pacing does and does not represent within the current evidence base.

RESULTS: A conceptual model including the core attributes of action, time, balance, learning and self-management emerged. From these attributes, an evidence-based definition for pacing was composed and distributed to stakeholders for review. After consideration of stakeholder feedback, the emergent definition of pacing was finalized as follows: "Pacing is an active self-management strategy whereby individuals learn to balance time spent on activity and rest for the purpose of achieving increased function and participation in meaningful activities".

CONCLUSION: The findings of the present concept analysis will help to standardize the use and definition of the term pacing across disciplines for the purposes of both pain management and research.
\end{abstract}

Key Words: Chronic pain; Concept analysis; Pacing; Self-management

$\mathrm{C}$ hronic noncancer pain (CNCP) is a common condition that affects individuals of all ages in a variety of ways that can cause suffering and disability $(1,2)$. CNCP has been described as pain that is both continuous and long-term, or as pain that persists after the expected healing time following injury (3). Prevalent CNCP conditions include fibromyalgia, chronic low back pain, chronic headaches, neuropathic pain and myofascial pain syndrome, among others (2). In 2010, $10.6 \%$ of Canadians reported suffering from moderate or severe pain, while $11.4 \%$ of Canadians reported that this pain interfered with their ability to participate in daily activities (4).

When pain becomes chronic, it can interfere with nearly every aspect of an individual's life including work, home, leisure and relationships (1). Individuals living with CNCP commonly experience disturbed sleep and a reduction in overall physical and mental functioning (2). CNCP is also associated with reductions in quality of life and the ability to adjust and adapt psychologically to new challenges and situations (5). Indeed, CNCP is characterized as significantly impacting physical health, emotional well-being and virtually every area of life (1).

Pain self-management strategies are central to CNCP treatment and are concerned with improving self-efficacy, reducing suffering and enhancing quality of life (6-8). The literature demonstrates that

\section{La régulation : l'analyse conceptuelle d'une intervention en douleur chronique}

HISTORIQUE : L'intervention de régulation est régulièrement recommandée chez les patients souffrant de douleurs chroniques. Cependant, le terme régulation est mal défini et semble interprété de manière variée et potentiellement contradictoire dans le domaine de la douleur chronique. Ce manque de clarté conceptuelle a des conséquences sur la prestation de services efficaces et pour la capacité des chercheurs à mener des études rigoureuses. L'examen des publications démontre que, même si la régulation fait souvent partie des programmes multidisciplinaires de gestion de la douleur, les recherches sur les issues sont entravées par l'absence de définition claire et commune de ce concept encore mal défini.

OBJECTIFS : Mener une analyse conceptuelle officielle du terme « régulation ».

MÉTHODOLOGIE : Les chercheurs ont utilisé une analyse conceptuelle normalisée (y compris l'établissement de la portée des publications pour déterminer toutes les utilisations du concept, l'analyse pour déterminer les caractéristiques décisives du concept ainsi que le modèle, les cas limites et contraires) pour déterminer ce que représente et ne représente pas le concept de régulation dans le cadre des données probantes actuelles.

RÉSULTATS : Un modèle conceptuel incluant les principales caractéristiques d'action, de temps, d'équilibre, d'apprentissage et d'autogestion a émergé. À partir de ces caractéristiques, les chercheurs ont composé une définition probante du terme régulation et l'ont distribuée aux intervenants afin qu'ils la révisent. Compte tenu des commentaires des intervenants, ils ont rédigé la définition émergente suivante du terme régulation : « La régulation est une stratégie d'autogestion active par laquelle les individus apprennent à équilibrer le temps consacré à l'activité et au repos afin d'accroître leur fonction et leur participation à des activités significatives. »

CONCLUSION : Les résultats de la présente analyse conceptuelle contribueront à normaliser l'utilisation et la définition du terme régulation entre les disciplines, tant pour ce qui est de la gestion de la douleur que de la recherche.

individuals with CNCP may experience a higher quality of life when the focus is shifted from a linear model of cause-and-effect focusing on cure toward the biopsychosocial model, which is more responsive to the complex nature of CNCP (9). A biopsychosocial approach emphasizes functional assessment, enhanced patient control and predictability, and strategies for self-management of pain (10). Research consistently demonstrates the importance of including psychological factors in the management of chronic pain (11). While a biomedical model focuses on the etiological and physiological explanations of chronic pain, a biopsychosocial model provides a framework incorporating not only these physiological processes, but also psychological and social-contextual variables that can perpetuate chronic pain (11). These three components of biological, psychological and social contexts interact and influence one another and, in turn, this influences the experience of chronic pain (11). The literature suggests that the biopsychosocial model is considered to be the most heuristic approach to chronic pain management (12).

Chronic pain has traditionally been managed through the use of both pharmacological and nonpharmacological treatment modalities (2). These may include analgesics, nerve blocks, opioids, physical therapy and behavioural interventions, among others (2). Many nonpharmacological treatment strategies that fall under the 
biopsychosocial model of pain management have also been used in chronic pain management, such as exercise, education, movement therapy, sensory stimulation, relaxation strategies, psychological approaches and pacing $(11,13)$. Within the biopsychosocial model, pacing has been used in chronic pain management with the goal of fostering self-management and self-efficacy (11). Indeed, pacing as an intervention appears with great regularity in the chronic pain management literature (14). For example, a survey of British occupational therapists determined that an essential component of their interventions in CNCP management was the use of activity pacing to counteract the overactivity-underactivity cycle that is perceived to be a common coping strategy of individuals with CNCP (15). However, what health care service providers actually mean by 'pacing' is unclear and poorly defined (14). Within a rehabilitation framework, the pacing concept represents a process of educating clients about alternating activity with rest (14). However, other uses of the term pacing are often built on operant conditioning principles, which reflect the principle of 'activity quota setting' to change reinforcement patterns $(16,17)$. In activity quota interventions, the expectation is of increased activity over time to achieve a target goal or 'quota'. The chronic pain literature suggests that there is a lack of general consensus regarding the conceptual foundations of the term pacing (15). Activity pacing may incorporate various concepts and foundations, including psychological and cognitive aspects, as well as operant and physical conditioning concepts (15). It is readily apparent from the literature that the term pacing is used to represent a variety of differing and, at times, contradictory concepts.

The implications of poor conceptualization of the term pacing in both theory and practice are significant (14). Ineffective service delivery can result from assumptions of common meaning and intent of pacing interventions (14). For example, if clinicians unknowingly apply different approaches to pacing within the same treatment program, the outcome may fail to result in effective pain management. This could lead to the abandonment of what may be a valuable intervention (15). Similarly, it is not possible to perform comparative reviews of pacing studies without clear definitions of how the intervention was conceptualized. Poor conceptualization can also lead to misinterpretation of the intervention itself, resulting in undesirable outcomes. For example, it has been suggested that pacing leads to activity avoidance (18). However, it is premature and erroneous to make these claims when health care professionals lack a clear and shared conceptual understanding of the intervention.

\section{Concept analysis}

Concept analysis is a systematic research method that is undertaken to examine the basic elements that compose an ambiguous or poorly defined concept (19). Concept analysis captures the critical elements of a concept for the purpose of facilitating understanding among stakeholders regarding the phenomena undergoing discussion (19). This approach is used with increasing regularity to clarify health care-related concepts such as empowerment (20) and quality of life (21). Walker and Avant (19) state that if a concept already exists in an area of interest, but is unclear or inconsistent, then concept development is warranted. The concept of pacing is such a case, in that it is a widely used term, but there is clear evidence that it is used inconsistently across and within groups of health care professionals.

A systematically conducted and reliable concept analysis is an important preliminary step for research and to further theoretical developments (19). In the case of pacing, a clear working definition and conceptualization would allow for research studies to be more easily replicated, facilitating the intervention studies that are needed for more effective service delivery (14). A recent structured review of the evidence of pacing as a chronic pain intervention revealed that pacing lacks both consensus of definition and a demonstrable evidence base (14). Therefore, the need for a comprehensive definition of pacing based on expert input and research exists (15). The aim of the present project was to undertake a concept analysis to begin the process of standardizing the use and evidence-based definition of the term pacing across health care disciplines' treatment and research activities.

\section{METHODS}

The present study was conducted in two stages. Stage one involved conducting the concept analysis detailed below. In stage two, a proposed definition of pacing was generated based on the attributes identified in stage one. The preliminary definition was then field-tested and feedback collected from a range of stakeholders.

\section{Steps 1 and 2: Concept analysis procedure}

Although there are several concept analysis methods, the method developed by Walker and Avant (19) was selected because of its extensive use in health care research. In general, a concept analysis involves a thorough examination of a concept and a description of how the concept is used within a language (19). The first two steps of the concept analysis process are to select a concept and to determine the aims of the analysis. These two steps have been presented in the introduction. The subsequent six steps in the process are outlined below.

Step 3. Identify all uses of the concept evidenced in the literature A search protocol was developed in consultation with a medical librarian to ensure that a thorough scope of the literature across relevant electronic databases was conducted. These databases included Scopus, Web of Science, Cumulative Index to Nursing and Allied Health Literature, Cochrane, OT Seeker, and Evidence-Based Medicine Reviews. Manual searches of references in the relevant literature were also performed.

A list of potential search terms was developed in consultation with a medical librarian (Appendix 1). The search was designed to encompass terms relating to pacing as an intervention for CNCP. Keywords for $\mathrm{CNCP}$ conditions used in the search were selected from the Canadian Pain Coalition website (http://prc.canadianpaincoalition.ca/fr/chronic_ pain_conditions.html) and then reviewed by an expert in the field of $\mathrm{CNCP}$ to determine whether they were comprehensive. Articles were considered for inclusion if they provided a definition of the term pacing and used the term pacing within the context of chronic pain. Articles were excluded if they did not provide a definition of pacing or did not use the term pacing within a chronic pain context. Language was limited to English, and no date limits were placed on the search. Duplicate records were removed and the results organized as a table (Table 1) to aid in efficient categorization of attributes and findings.

\section{Step 4. Defining attributes}

Identifying the defining attributes of a concept analysis is used to demonstrate the unique cluster of attributes that are most often associated with the concept and that allow for the broadest insight into the concept (19). Definitions and uses of pacing found in the literature search were analyzed by two authors (KJL, RB). The third author (CB) was consulted for consensus or involvement when disagreements arose. Articles were reviewed to identify the common attributes of pacing. The defining attributes were identified as those that arose frequently and consistently.

\section{Step 5. Identify a model case}

A model case integrates all of the defining attributes of a concept, and reflects a 'pure case' of the concept at hand (19). A model case was constructed to capture all of the defining attributes of pacing.

\section{Step 6. Identify borderline and contrary cases}

Borderline and contrary cases represent inaccurate usage of the concept because they typically incorporate none or only some of the defining attributes (19). Borderline and contrary cases are presented to clarify and provide examples of inaccurate representations of the concept of pacing as constituted with pacing's unique attributes and within the context of CNCP.

\section{Step 7. Identify antecedents and consequences}

Antecedents are the events or conditions required for the concept to occur, while consequences are the outcomes of the concept (19). The 
TABLE 1

Attributes of pacing identified in included studies

Defining attribute

Self-

\begin{tabular}{|c|c|c|c|c|c|}
\hline Author (reference) & Activity & Time & Balance & Learning & management \\
\hline Beissner et al (39) & $x$ & & & $x$ & $x$ \\
\hline Berger (33) & $x$ & $x$ & $x$ & $x$ & \\
\hline Birkholtz et al (15) & & & $x$ & $x$ & $x$ \\
\hline Cane et al (23) & $x$ & & & $x$ & $x$ \\
\hline Cane et al (24) & $x$ & $x$ & $x$ & $x$ & $x$ \\
\hline De Williams et al (40) & $x$ & $x$ & & $x$ & $x$ \\
\hline Ersek et al (25) & $x$ & $\mathrm{X}$ & & $x$ & $\mathrm{X}$ \\
\hline Gill and Brown (14) & & & $x$ & $x$ & $x$ \\
\hline Johansson et al (28) & $x$ & & $x$ & $x$ & \\
\hline $\begin{array}{l}\text { Karsdorp and Vlaeyen } \\
\text { (27) }\end{array}$ & $x$ & $x$ & & $x$ & $x$ \\
\hline Marhold et al (34) & $x$ & & $x$ & $x$ & \\
\hline Meeus et al (35) & $x$ & & $x$ & $x$ & $x$ \\
\hline Molton et al (31) & $\mathrm{X}$ & $x$ & & $x$ & $x$ \\
\hline Murphy et al (29) & $x$ & $x$ & & $x$ & $x$ \\
\hline Neilson et al (30) & $x$ & $x$ & & $x$ & $x$ \\
\hline Nijs et al (36) & $x$ & & $x$ & $x$ & $x$ \\
\hline Nijs et al (37) & $\mathrm{x}$ & $\mathrm{X}$ & $x$ & $x$ & $x$ \\
\hline Nijs et al (41) & $\mathrm{X}$ & $\mathrm{X}$ & $x$ & $x$ & $\mathrm{X}$ \\
\hline $\begin{array}{l}\text { Rundell and Davenport } \\
\text { (32) }\end{array}$ & $x$ & $x$ & & $x$ & $x$ \\
\hline Shepherd (38) & $x$ & & $x$ & $x$ & \\
\hline Sumpton and Moulin (42) & & & $x$ & $\mathrm{X}$ & \\
\hline Turner et al (43) & $x$ & & & $x$ & \\
\hline Van Huet et al (26) & $x$ & $x$ & $\mathrm{x}$ & $x$ & $x$ \\
\hline Van Lankveld et al (44) & $x$ & & & $x$ & \\
\hline Widner and Zeichner (45) & & $x$ & & $x$ & \\
\hline Williams et al (46) & $x$ & $x$ & & $x$ & \\
\hline
\end{tabular}

antecedents and consequences were determined for the concept of pacing by identifying common events that occurred before and as a result of pacing within the $\mathrm{CNCP}$ literature and from goals of treatment identified in the website summaries that were accessed from pain management programs.

\section{Step 8. Define empirical referents}

The final step in completing a structured concept analysis is to determine the empirical referents of a concept (19). The empirical referents for pacing were identified through determining which phenomena demonstrate that pacing has occurred.

\section{RESULTS}

General use of the term pacing

According to the Oxford Concise Dictionary (22) the term 'pacing' has a variety of definitions across a range of contexts:

1. Walk at a steady speed, especially without a particular destination and as an expression of anxiety.

- Measure (a distance) by walking it and counting the number of steps taken.

2. Move or develop (something) at a particular rate or speed

- Lead (another runner in a race) in order to establish a competitive speed.

3. (pace oneself) Do something at a restrained and steady rate or speed.

4. Cardiac pacing - regulation of the rate of contraction of the heart muscle by an artificial cardiac pacemaker

5. Normal gait of some horses.

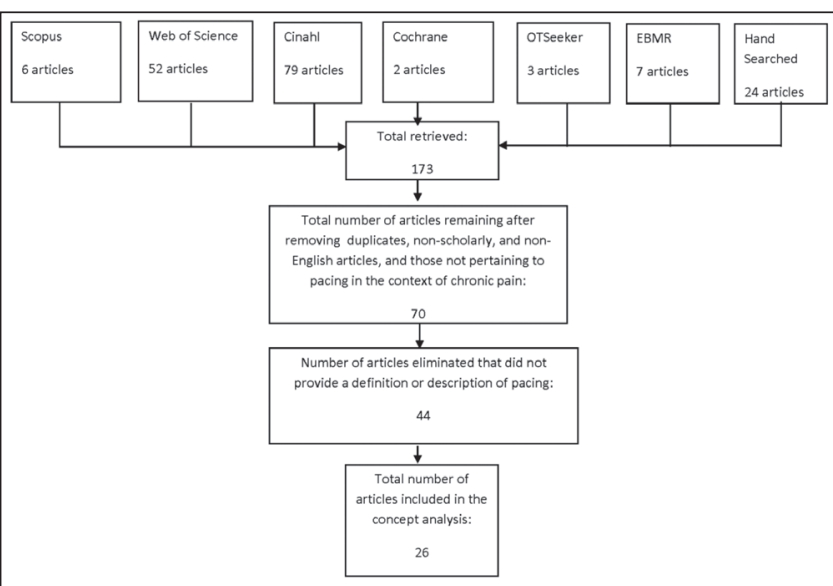

Figure 1) Database search results

6. Stereotyped pacing; a habit in all caged animals, especially if they are active species and are confined in very small areas. May cause excessive wear in footpads, in snakes the damage is usually to the front of the head.

7. Setting the pace or rate of movement.

Pain management use of the term pacing

Figure 1 summarizes the literature search and screening results. The literature revealed that pacing is a common intervention mentioned in research on CNCP management programs. Despite this, only 26 of the original 173 articles retrieved in the search provided an actual definition of pacing or precisely what it entails. In fact, 44 articles were excluded from the analysis due to their failure to provide a description or definition of pacing. In the articles included in the analysis, pacing was used in chronic pain treatment modalities offered by a variety of health care professionals including occupational therapists, physiotherapists and psychologists. The goal of pacing was most commonly described in terms of pain management $(15,23-32)$. The most frequently used methods for pacing included breaking down activities into manageable components $(23,25,28,33-38)$ and balancing or alternating between activity and rest $(15,23,28,33-38)$.

\section{Defining attributes}

Five defining attributes were consistently evident (Table 1):

1. Action. There is an active component to pacing, meaning that the individual requires active involvement in the process. Pacing is not passive; it requires intent on behalf of the individual.

2. Time. Pacing has a temporal dimension in that it occurs over time and requires conscious attention to time.

3. Balance. Pacing requires balanced participation on behalf of the individual between activity and rest. Balance in this context did not necessarily focus on equitable (50/50) distribution of time spent in either activity or rest. Rather, balance was concerned with relative weighting of each component to achieve satisfactory outcomes.

4. Learning. Pacing involves learning; it is not an innate action Instead, it is a conscious effort or choice to acquire knowledge or skills relevant to pacing to manage pain.

5. Self-management. Pacing involves self-management in that it involves independently guiding oneself through the process once the skill itself has been learned.

\section{Definition}

Based on the identified defining attributes, the following definition of pacing was proposed, presented at two scientific conferences and forwarded to stakeholders for review:

Pacing is an active self-management strategy whereby individuals develop self-efficacy through learning to balance time spent on activity and rest for the purpose of achieving increased function. 


\section{BOX 1 (Model case)}

Stan is a 58-year-old retired bus driver who had been diagnosed with low back pain. He quit his job six months ago as his pain was interfering with his ability to perform his job. Stan's roles around the home primarily included home and yard maintenance and meal preparation. On days when his pain was manageable, Stan felt himself trying to do as many daily tasks as possible, eg, shopping at the grocery store, vacuuming the house, fixing the flat tire on his granddaughter's bicycle and making dinner. On subsequent days, however, Stan's pain can be so debilitating that he is unable to perform even the most basic self-care activities without severe pain. Stan feels frustrated and dissatisfied in the way that he was unable to perform meaningful activities without his pain interfering.

Stan began attending educational sessions at a local pain clinic that included pacing education as an intervention strategy. The weekly pain management classes were led by a clinical psychologist and an occupational therapist. He learned to balance the time spent on activities to avoid overactivity and underactivity. Since attending the educational sessions, Stan feels able to manage his chronic pain more effectively. He has been able to achieve a balance between rest and activity, and is able to perform meaningful activities with less pain interference.

\section{BOX 2 (Borderline case)}

Mary was recently diagnosed with chronic daily headaches and was attending a chronic pain management program to learn skills for managing her pain. Part of the program involved learning about pacing. In the pacing sessions, participants were asked to think of an activity that they were no longer able to participate in because of their pain. With this activity they were encouraged to establish their baseline tolerance time for doing the activity, and then gradually increase this time by five minutes daily with the intention of increasing tolerance for participating in the activity. Mary identified that her headaches made reading very difficult Using the above approach, Mary cut back on her afternoon craft activities and took a 15 minute nap so that she could increase the amount of time she was able to tolerate reading her children's homework in the evening at home. She was able to participate longer in the parenting role but was dissatisfied that this was at the cost of her valued leisure activity.

\section{Model case}

A model case is an example of the use of the concept in which all defining attributes are evident and is, therefore, considered an accurate reflection of the concept in use (19).

In this model case (Box 1) the patient has demonstrated the five defining attributes of pacing: action, time, balance, learning and selfmanagement. The model case illustrates that the patient now understands and controls the problem of overactivity and underactivity and is independently able to manage pain to participate in personally meaningful roles and activities.

\section{Borderline case}

A borderline case uses some, but not all, of the defining attributes of the concept (19). A borderline case is, therefore, not an accurate reflection of the concept. Box 2 is an example of a borderline case for pacing.

In this example, the patient demonstrates the attributes of action, time, learning and self-management. The attribute of balance, however, is not present. One rewarding activity has been compromised to achieve gains in another required, but less personally rewarding, activity. Although the process has resulted in a positive outcome, it does not involve all of the defining attributes of pacing and, therefore, cannot be labelled as such. It is possible that this example more closely reflects the idea of 'activity management' as opposed to pacing.

\section{Contrary case}

A contrary case (Box 3 ) provides a clear example of what the concept is not (19).

\section{BOX 3 (Contrary case)}

Cathy's neck and shoulder pain often acted as a barrier to her completing activities of daily living. Cathy specifically had difficulty completing daily household chores, and described how even the most basic chores resulted in increased neck and shoulder pain. Cathy was fearful that such activities might in fact cause further injury to her neck and shoulder and as a result spent much of her time inactive, passively watching television. On days on which her pain lessened, Cathy was motivated to complete chores around the house. On these days she would engage in cleaning activities for many hours. This invariably resulted in significantly worse pain requiring a period of recovery over the next several days. During these recovery periods Cathy found that she spent most of her time lying supine on her sofa. This activity pattern was routine in Cathy's life and resulted in her experiencing feelings of anxiety, anger and frustration.

In this example, a balance between activity and rest does not exist, the skills of pacing have not been learned and there is a lack of self-management in performing household activities. This example illustrates the circumstances of over- and underactivity, in which participation in meaningful activities is dictated by pain levels rather than individual desire or motivation.

\section{Antecedents and consequences}

From the reviewed literature, it appears that the antecedents that must be present before the implementation of pacing include activity disruption secondary to pain, imbalance between activity and rest, patient's lack of pain self-management knowledge and pain itself. The consequences of pacing that emerged from the literature review included pain management, self-direction and improved self-efficacy, avoidance of pain exacerbation, balanced activity/rest, increased functional ability, and increased knowledge and skills in activity planning and prioritizing. Because the use of pacing in the present analysis is in the context of chronic pain, the antecedents reflect the events and situations associated with the experience of having a chronic pain condition, and the consequences are the anticipated outcomes one would expect of an individual who has successfully learned to pace.

\section{Empirical referents}

Empirical referents are measures or observations that provide evidence that the concept is occurring or has occurred (19). Empirical referents for pacing include direct observation of pacing behaviours, patient self-report and written evidence in the form of activity logs or records that demonstrate pacing activity. For example, an activity log might reveal that a balance between activity and rest has been achieved. Observing a friend or family member participating in meaningful activities on a daily basis rather than only on 'good days' might also provide evidence that pacing is occurring. Chronic pain programs that incorporate pacing education may have their own empirical referents that serve as evidence. No formal outcome measures were identified in the reviewed literature that were direct empirical referents for pacing.

\section{Stage 2: Definition generation and field testing}

A proposed definition for the concept of pacing was developed based on the identified attributes. To improve rigour, the attributes and resulting definition were presented at an international multidisciplinary conference (British Pain Society/Canadian Pain Society Joint Annual Scientific Meeting 2011, Edinburgh, Scotland) and a national conference (Canadian Association of Occupational Therapy Annual Conference 2011, Saskatoon, Saskatchewan), at which interested stakeholders were invited to provide input and feedback. Stakeholders provided their e-mail addresses and identified that they were interested in participating in the ongoing discussion. Additionally, 14 stakeholders from a range of disciplines who had corresponded about pacing with the project supervisor over the past several years were contacted. The proposed defining attributes and definition of pacing were e-mailed to all stakeholders and they were 
invited to provide feedback and comments. Ten of the 22 stakeholders invited to comment on the defining attributes and definition of pacing provided feedback. A variety of insightful comments both supporting and questioning the defining attributes and the definition of pacing were provided by stakeholders.

More respondents commented on the definition of pacing than on the defining attributes. Although most stakeholder feedback was supportive of the defining attributes, some believed that the identified attributes fell short of describing what exactly is happening when pacing occurs. Specifically, the attribute of 'balance' resulted in the greatest amount of concern and discussion. Comments questioned the idea of balance in terms of equal participation between activity and rest, ambiguity behind the meanings of words such as 'activity' and 'rest', and how balance relates to choosing or planning participation in meaningful activities. More respondents were in favour of the attributes of time, learning and self-management, and no disagreements were identified with the attribute of action.

An equal response between those who agreed and disagreed was observed with the proposed definition. Disagreements were largely due to the inclusion of 'self-efficacy' as a consequence of an individual learning to pace. The implications behind the words 'activity' and 'rest' were also questioned, with some commenting on the fear that 'rest' may lead to activity avoidance, and others suggesting that 'activity' is not a clear-cut term and can, in fact, imply a variety of different things. For example, an activity can be restful, which leads to the question of whether it falls under 'activity' or 'rest'. Some questioned whether the definition should be expanded to include other elements that improve with pacing such as lifestyle balance, pain management and participation in meaningful activities.

A number of respondents described their concerns regarding the use of pacing in practice in general. Most notable were concerns regarding the consequences of providing inaccurate or overly simplistic pacing advice. Others commented on the importance of educating clients about both the physiological and psychological aspects of pacing to provide an accurate and comprehensive understanding of the process. Finally, it was noted that the term pacing may be used quite differently between health care providers and clients.

Stakeholders' responses received repeated readings and discussion by the research team. As part of the concept analysis process, the stakeholders' comments were considered as the definition was refined. Revisions needed to remain congruent with what was uncovered in the preliminary literature search and, as such, reflect the current state of the concept as opposed to what some stakeholders proposed was the ideal definition. Ultimately, the original proposed definition was revised, with two key modifications. First, 'self-efficacy' was removed from the definition. This decision was based on stakeholder feedback and agreement between members of the research team that self-efficacy, although an anticipated consequence of successful pacing, is not the primary purpose of pacing that emerged from the literature. Second, the section of the definition regarding learning to balance activity and rest for the "purpose of achieving increased function" fell short of the desired intent of pacing. Stakeholders highlighted that pacing facilitates lifestyle balance and participation in meaningful activities, both of which describe the fundamental purpose of pacing. This portion of the definition was amended to read "...for the purpose of achieving increased function and participation in meaningful activities."

Following the revisions, the proposed definition for the concept of pacing in chronic pain is as follows:

"Pacing is an active self-management strategy whereby individuals learn to balance time spent on activity and rest for the purpose of achieving increased function and participation in meaningful activities."

\section{DISCUSSION}

The aim of the present research was to clarify and promote a common conceptualization of pacing through the process of a formal concept analysis (19). This is important because while pacing as a self-management intervention for chronic pain appears frequently in the literature, the term lacks consistency of use. In stage two of the concept analysis, we found that stakeholder perspectives varied greatly and revealed a diversity of opinions on what pacing means and how it should be used in practice. Comments frequently reflected what stakeholders would like to see as the defining attributes based on opinion and practice experience as opposed to our objective findings that emerged from the existing evidence base.

The antecedents and consequences we proposed related to CNCP are based on our clinical knowledge of patients' experiences and the goals of pain management programs. We recognize that the consequence of achieving balance between activity and rest does not imply equal participation in each, but rather a balance that is conducive to achieving both participation in activities of daily living and pain management. In our concept analysis, we understood pain management to be a process of "handling the pain by using certain actions and by directing and controlling one's own use of these actions" (39). If this is the case, then teaching the process of pacing in a pain management program has the intent that individuals will learn the skills and have the capacity to pace independently in their own communities and environments, thereby removing the need for ongoing professional monitoring. Pacing is also expected to reduce the problem of over- and underactivity, thereby eliminating periods of pain exacerbation. From the literature, it appeared that although patients who learn to pace may report some decrease in pain intensity, pain reduction was not anticipated as a primary outcome. The concern raised by some stakeholders that pacing might lead to activity avoidance and decreased function is echoed in some of the background literature $(18,25)$. Several stakeholders stated they had completely eliminated the term pacing from their pain management programs due to the possible relationship between pacing and activity avoidance. We propose that the consequence of activity avoidance is the result of a lack of conceptual clarity leading to misunderstanding by either the client or health care professional as to the meaning of pacing, rather than a direct consequence of accurate engagement in pacing strategies. It is possible that patient education that focuses on time budgeting as a strategy (as reflected in the borderline case example) could erroneously be labelled as pacing and, therefore, inadvertently lead to concerns relating to activity avoidance in which specific time limits dictate activity participation. Furthermore, the elimination of the term 'pacing' from chronic pain programs altogether and replacing it with a different term, such as 'activity management', does not resolve the problems of conceptual ambiguity. The words may change but the problem remains the same. We suggest that activity avoidance is not a consequence of pacing as conceptualized in the present study and eliminating the word 'pacing' from pain management programs will not resolve this issue.

The proposed empirical referents for pacing provided in the present analysis emerged from the literature and highlight the underdevelopment of objective and standardized outcome measures for the intervention of pacing. Our review revealed that some work has been performed to develop a pacing subscale for the Chronic Pain Coping Inventory (30). However, the intention of this subscale is to identify behaviours associated with pacing, including 'going slower', 'taking breaks', 'maintaining a steady pace' and 'breaking tasks down into manageable pieces' (30), and the selection of these particular behaviours do not necessarily align with the defining attributes of pacing identified in our review of the evidence base. Further research is clearly needed but cannot move forward until CNCP researchers arrive at some basic agreement as to what constitutes the concept of pacing.

\section{Implications for practice}

The lack of a common definition and understanding of the concept of pacing in the context of CNCP compromises the evidence in this area of practice. In the CNCP pacing literature, there is uncertainty as to what precisely is being evaluated. Although the findings of such studies may be valid, they invariably lack clarity because the 
definition of the concept is not shared. This compromises the ability to generalize results, further reducing the ability to deliver evidencebased interventions to patients. We suggest it is essential for health care providers to revisit their use of the word pacing and evaluate its conceptual clarity against the proposed definition derived from the present concept analysis. This is a first step in achieving uniformity and conceptual clarity.

The range of domains associated with pacing suggests that educating patients about pacing is not a simple, straightforward process. An understanding by health care providers of both the psychosocial and physiological aspects related to pacing is required and pacing education strategies need to take this into consideration. Interventions based on a poor or inaccurate conceptualization of pacing may be a barrier to patient success.

\section{Future research}

It is evident that further research is needed to achieve congruency with the use of pacing in both clinical practice and research. Stakeholders' diverse ideas and perspectives regarding what pacing is and how it should/could be applied as an intervention were evident. Additionally, uncertainty underlying the meanings of often-used pacing terms, such as 'balance', 'activity' and 'rest', emphasizes that further efforts to clarify these concepts are also warranted.

The gap in knowledge between what pacing means to health care providers versus what it means to patients also needs to be addressed. Versions of pacing information are publicly available through online pain websites, information brochures and pamphlets, and pain management books. It is important to identify both the similarities and the inconsistencies that occur between these resources and the health care literature. A concept analysis of pacing based on publicly available information would help to determine the extent of any existing discrepancies.

Finally, the term 'activity management' appeared on numerous occasions during the process of the present concept analysis. Reflecting on the issues that have emerged from pacing's lack of conceptual clarity, it appears important to establish precisely what activity management entails in its use in CNCP management while still in its early stages of use.

\section{Limitations}

The search was limited to online databases and to research published in English. It is possible that relevant grey literature, unpublished reports or non-English language material was missed through this process. Additionally, feedback from stakeholders was opportunistically gathered and a more structured approach may have resulted in more comprehensive insight into health care providers' beliefs regarding the term pacing.

\section{Conclusions}

The inconsistent and undefined concept of pacing has negative implications for practice and for research. The present concept analysis provides an examination of the chronic pain literature for the purpose of refining the concept of pacing. Based on the results of the present concept analysis, in the context of $\mathrm{CNCP}$, the following definition of pacing emerged:

"Pacing is an active self-management strategy whereby individuals learn to balance time spent on activity and rest for the purpose of achieving increased function and participation in meaningful activities."

The lack of definition and conceptual consistency of the term pacing solidifies the importance of continued work to clarify ambiguity and promote uniform application of the term within the literature. We encourage other stakeholders to join us in this continuing work.

ACKNOWLEDGEMENTS: The authors thank all of the health care providers and researchers who generously provided feedback on the attributes and definition, and Linda Seale, Senior Medical librarian, for her assistance with the search strategy.

\section{APPENDIX 1}

Databases searched:

- Scopus

- Web of science

- CINAHL

- Cochrane

- OT Seeker

- EMBR (Ovid)

Hand search of reference lists

Initial search terms used:

"prolonged pain" OR "long term pain" OR "recurrent pain" OR "intractable pain" OR "untreatable pain" OR pain OR "chronic pain" OR "Diabetic neuropathy" OR Shingles OR "Post-herpetic neuralgia" OR "Neuropathic pain" OR "Complex regional pain syndrome" OR "Trigeminal neuralgia" OR Fibromyalgia OR "Myofascial pain syndrome" OR "Central sensitization" OR "Pelvic pain" OR Vulvodynia OR "Pudendal neuralgia" OR "Interstitial cystitis" OR Dysmenorrhea OR Migraine OR "Tension type headache" OR "Cluster headache" OR "Cervicogenic headache" OR "Temporomandibular joint disorder" OR Osteoarthritis OR "Sacro-iliac joint pain" OR "Piriformis syndrome" OR "Facet arthropathy" OR "Spinal stenosis" OR "Degenerative disc disease" OR Sciatica OR "Whiplash-associated disorder" OR "Chronic fatigue syndrome"

AND

"activity pacing" OR pacing OR pace

AND

"self management" OR "pain coping" OR "pain management" OR "pain treatment"

Limits: English Language

Modified search to increase selectivity:

"Chronic pain"

AND

"activity pacing" OR pacing OR pace

AND

"self management" OR "pain coping" OR "pain management" OR "pain treatment"

Limits: English Language

\section{REFERENCES}

1. Millar WJ. Chronic Pain. Health Rep 1996;4:47-53.

2. Spacek A. Modern concepts of acute and chronic pain management. Biomed Parmacother 2006;60:329-35.

3. British Pain Society. < www.britishpainsociety.org/media_faq.htm> (Accessed July 20, 2011).

4. Statistics Canada. Health Trends. 2011. <www12.statcan.gc.ca/ health-sante/82-213/index.cfm?Lang=ENG> (Accessed July 20, 2011).

5. Meana M, Cho R, DesMeules M. Chronic Pain: The extra burden on Canadian women. Women's Health Surveillance Report: Statistics Canada. <www.phac-aspc.gc.ca/publicat/whsr-rssf/pdf/ WHSR_Chap_16_e.pdf> (Accessed July 3, 2011).

6. Miles CL, Pincus T, Carnes D, Taylor SJ, Underwood M. Measuring pain self-efficacy. Clin J Pain 2011;27:461-70.

7. Carnes D, Homer KE, Miles CL, et al. Effective delivery styles and content for self-management interventions for chronic musculoskeletal pain: A systematic literature review. Clin J Pain 2012;28:344-54.

8. Hardy PAJ. Chronic Pain Management: The Essentials. London: Greenwich Medical Media, 1997.

9. Main CJ, Williams A. ABC of psychological medicine: Musculoskeletal pain. BMJ 2002;325:534-7.

10. Ramage-Morin PL. Chronic pain in Canadian seniors. Statistics Canada website. February, 2008. <www.statcan.gc.ca/pub/82-003x/2008001/article/10514-eng.pdf> (Accessed March 20, 2011).

11. Turk JA, Okifuji A. Psychological factors in chronic pain: Evolution and revolution. J Consult Clon Psychol 2005:70;471-9.

12. Gatchel RJ, Peng YB, Peters ML, Fuchs PN, Turk DC.

The biopsychosocial approach to chronic pain: Scientific advances and future direction. Psychol Bull 2007:133;581-624. 
13. Mannerkorpi K, Henriksson C. Non-pharmalogic treatment of chronic widespread musculoskeletal pain. Best Pract Res Clin Rheumatol 2007:21;513-34.

14. Gill JR, Brown CB. A structured review of the evidence for pacing as a chronic pain intervention. Eur J Pain 2009:13;214-6.

15. Birkholtz M, Aylwin L, Harman RM. Activity pacing in chronic pain management: One aim, but which method? Part one: Introduction and literature review. Br J Occup Ther 2004:67;447-52.

16. Fordyce WE. Behavioral methods for chronic pain and illness. St. Louis: Mosby, 1976.

17. Keefe FJ. Cognitive behavioral therapy for managing pain. Clin Psychol 1996:49;4-5.

18. McCracken LM, Samuel VM. The role of avoidance, pacing, and other activity patterns in chronic pain. Pain 2007:130;119-25.

19. Walker LO, Avant KC. Strategies for theory construction in Nursing, 4th edn. New Jersey: Pearson Prentice Hall, 2005.

20. Ryles S. A concept analysis of empowerment: Its relationship to mental health nursing J Adv Nurs 1999:29;600-7.

21. Meeberg GA. Quality of life: A concept analysis. J Adv Nurs 1993:18;32-8.

22. Soanes C, Stevenson A. The Concise Oxford English Dictionary, 11th edn. New York: Oxford University Press, 2008.

23. Cane D, McCarthy M, Lynch M, et al. Coping with pain: Prevalence of pacing in patients attending a multidisciplinary pain treatment program. J Pain 2004:3;S95.

24. Cane D. Nielson W, Mazmanian D. A comparison of two measures of pain-related activity patterns. Abstract \# 36. [Canadian Psychological Association website]. June, 2008. <www.cpa.ca/ cpasite/UserFiles/Documents/convention/2008\%20 Convention/2008\%20Abstract\%20Book/Friday\%20June\%20 13,\%202008.pdf> (Accessed December, 2011).

25. Ersek M, Turner JA, Kemp CA. Use of the chronic pain coping inventory to assess older adults' pain coping strategies. J Pain 2006:11;833-42.

26. Van Huet $\mathrm{H}$, Innes E, Whiteford G. Living and doing with chronic pain: Narratives of pain program participants. Disabil Rehabil 2009:24:2031-40.

27. Karsdorp PA, Vlaeyen JW. On the validity of 'activity pacing'. Comment on Jensen "research on coping with chronic pain: The importance of active avoidance of inappropriate conclusions". Pain 2009:147;305.

28. Johansson C, Dahl JA, Jannert M, et al. Effects of a cognitive-behavioral pain-management program. Behav Res Ther 1998:10;915-30.

29. Murphy SL, Smith DM, Alexander NB. Measuring activity pacing in women with lower-extremity osteoarthritis: A pilot study. Am J Occup Ther 2008:3;329-34.

30. Nielson WR, Jensen MP, Hill ML. An activity pacing scale for the chronic pain coping inventory: Development in a sample of patients with fibromylagia syndrome. Pain 2001:89;111-5.

31. Molton I, Jensen MP, Ehde DM, Carter GT, Kraft G, Cardenas DD. Coping with chronic pain among younger, middle-aged, and older adults living with neurological injury and disease. J Aging Health 2008:8;972-96.
32. Rundell SD, Davenport TE. Patient education based on principles of cognitive behavioral therapy for a patient with persistent low back pain: A case report. J Orthop Sports Phys Ther 2010:40;494-501.

33. Berger P. Perspectives on physiotherapy guidelines for chronic low back pain. S Afri J Physiother 2007;3:15-21.

34. Marhold C, Linton SJ, Melin L. A cognitive-behavioural return-towork program: Effects on pain patients with a history of long-term versus short-term sick leave. Pain 2001:91;155-63.

35. Meeus M, Nijs J, Van Oosterwijck J, Van Alsenoy V, Truijen S. Pain physiology education improves pain beliefs in patients with chronic fatigue syndrome compared with pacing and selfmanagement education: A double-blind randomized controlled trial. Arch Phys Med Rehabil 2010:91;1153-9.

36. Nijs J, Meuss M, De Meirleir K. Chronic musculoskeletal pain in chronic fatigue syndrome: Recent developments and therapeutic implication. Man Ther 2006:11;187-91.

37. Nijs J, Paul L. Wallman K. Chronic fatigue syndrome: An approach combining self-management with graded exercise to avoid exacerbations. J Rehabil Med 2008:40;241-7.

38. Shepherd C. Pacing and exercise in chronic fatigue syndrome. Physiotherapy 2001:87;395-6.

39. Beissner K, Henderson CR, Papaleontiou M, Olkhovskaya Y, Wigglesworth J, Reid MC. Physical therapists' use of cognitivebehavioral therapy for older adults with chronic pain: A nationwide survey. Phys Ther 2009;89:456-69.

40. De C Williams AC, Nicholas MK, Richardson PH, Pither CE, Fernandes J. Generalization from a controlled trial: The effects of patient preference versus randomization on the outcome of inpatient versus outpatient chronic pain management. Pain 1999:83;57-65.

41. Nijs J, Van Eupen I, Vandecauter J, et al. Can pacing selfmanagement alter physical behavior and symptom severity in chronic fatigue syndrome? A case series. J Rehabil Res Dev 2009:46;985-96.

42. Sumpton JE, Moulin DW. Fibromyalgia: Presentation and management with a focus on pharmacological treatment. Pain Res Manag 2008:13;477-83.

43. Turner JA, Ersek M, Kemp C. Self-efficacy for managing pain is associated with disability, depression, and pain coping among retirement community residents with chronic pain. J Pain 2005:6;471-9.

44. Van Lankveld W, Bosch P, Van De Putte L, Naring G, van der Staak C. Disease-specific stressors in rheumatoid arthritis: Coping and well-being. Rheumatology 1994:33;1067-73.

45. Widner S, Zeichner A. Psychologic interventions for the elderly chronic pain patients. Clin Gerontol 1993:13;3-18.

46. Williams AC, Nicholas MK, Richardson PH, et al. Evaluation of a cognitive-behavioral program for rehabilitating patients with chronic pain. Br J Gen Pract 1993:43;513-8. 


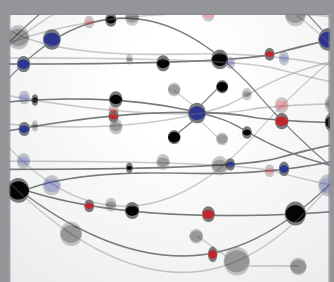

The Scientific World Journal
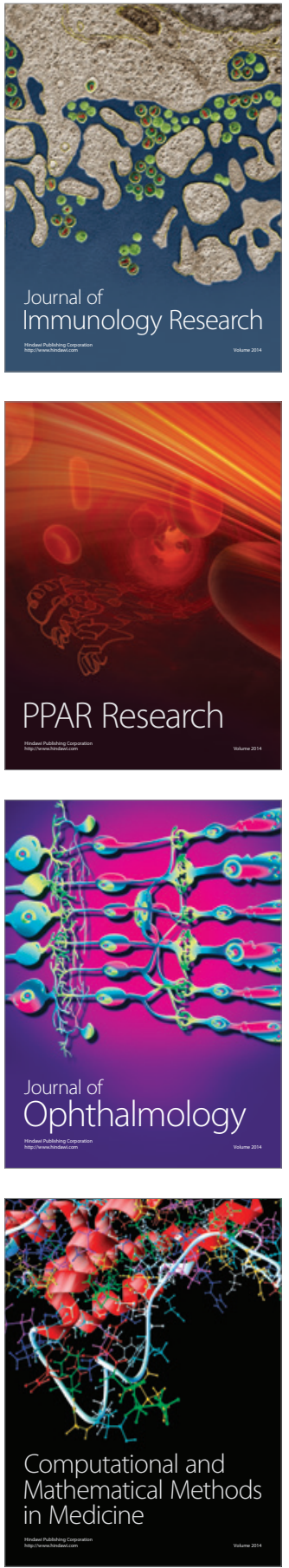

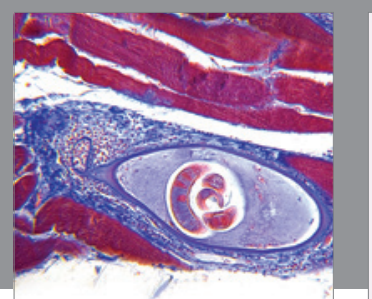

Gastroenterology Research and Practice

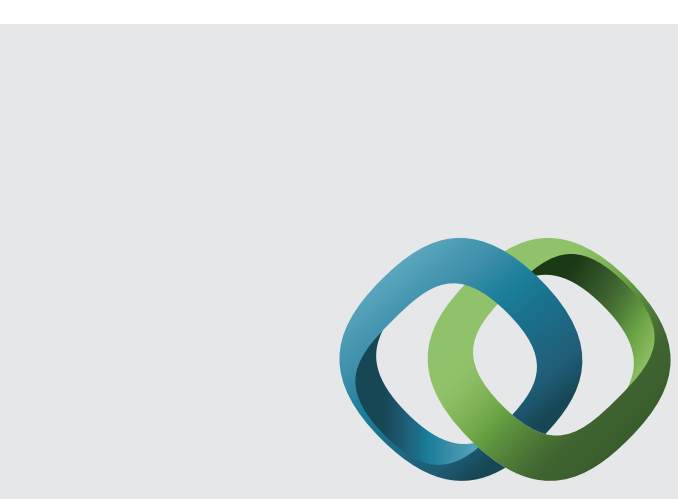

\section{Hindawi}

Submit your manuscripts at

http://www.hindawi.com
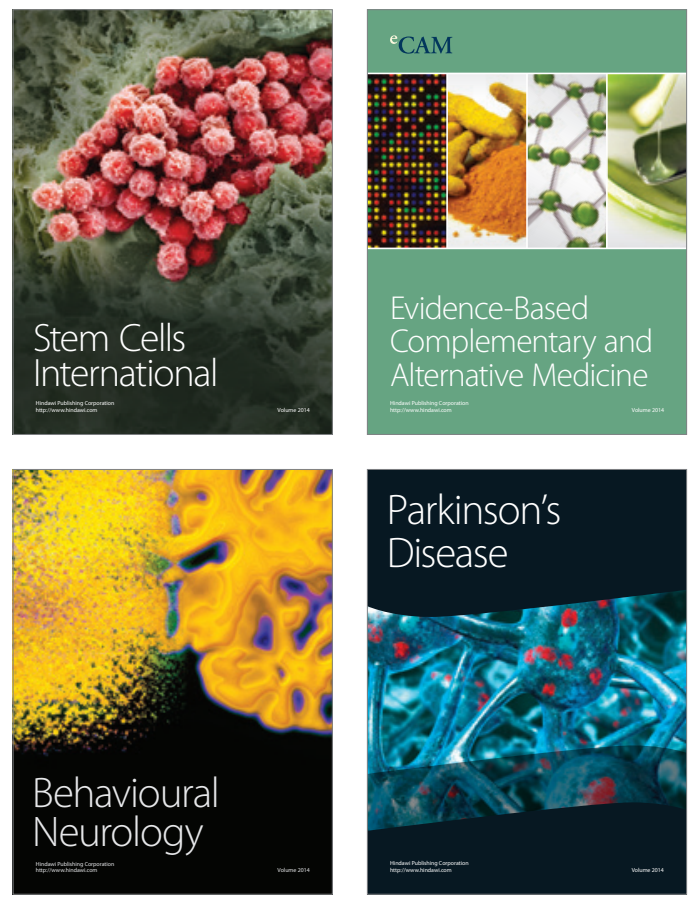
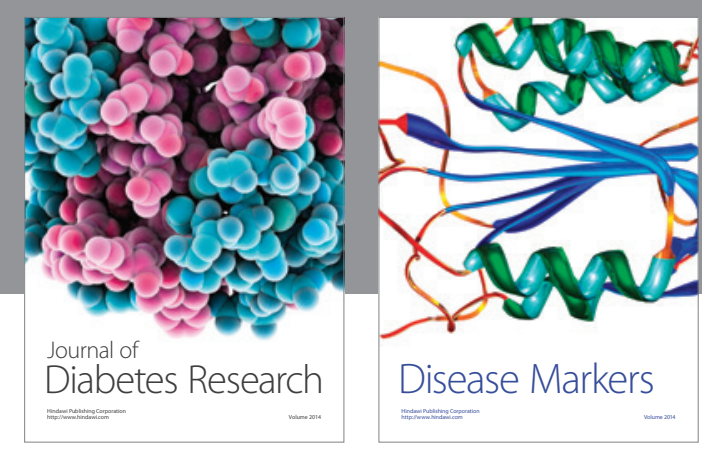

Disease Markers
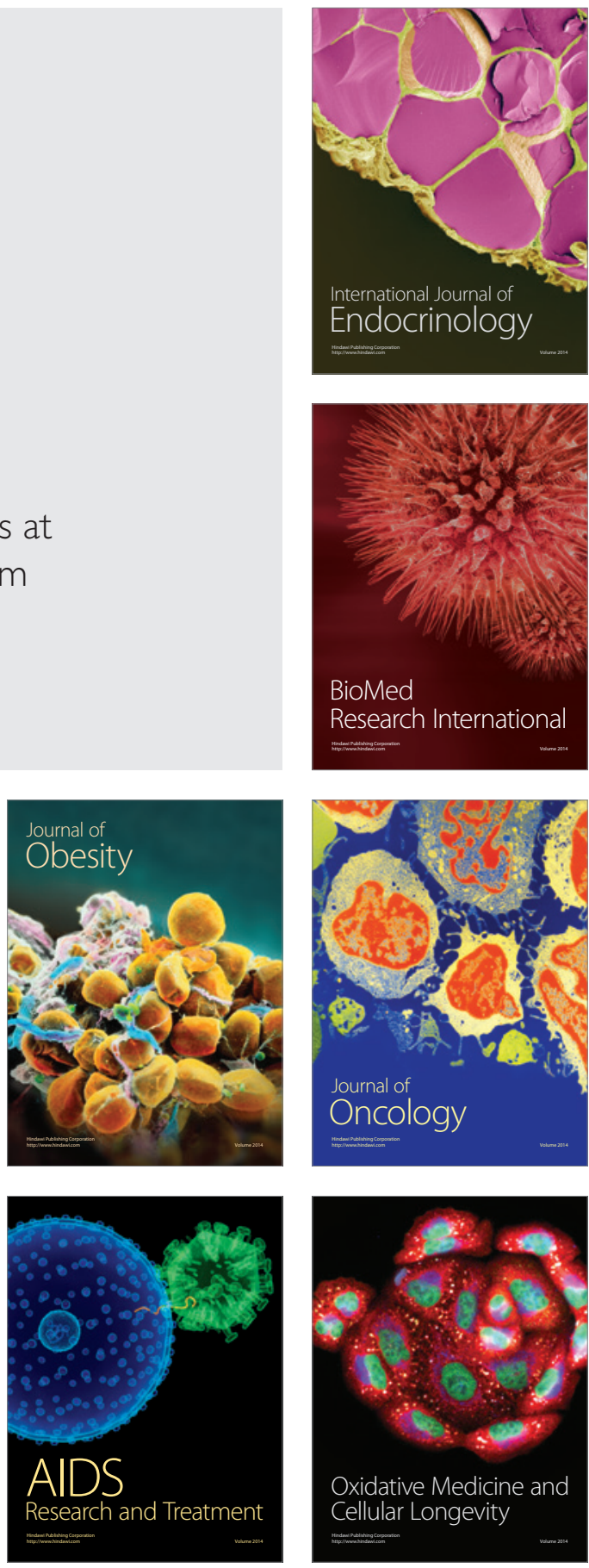